\section{Outstanding technology}

Special show offers, an interactive theatre experience and CPD were all available from Waterpik at the recent BDIA Dental Showcase held on 4-6 October 2018 in London. The innovative Waterpik Whitening Water Flosser was on display, which is clinically proven to remove

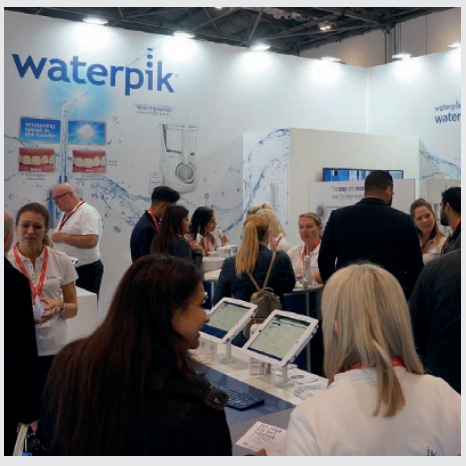
up to $99.9 \%$ of plaque from treated areas and to be up to $50 \%$ more effective for improving gum health than string floss.

In addition, the Water Flosser helps improve natural tooth whiteness in four weeks by gently removing up to $25 \%$ more stains than brushing alone and reaching hard-to-reach areas that other products miss.

For more information on Waterpik, visit www.waterpik.co.uk.

\section{Free smile events}

To build on the rapidly growing interest in digital dentistry, Align Technology is rolling out a series of Free Smile Assessment events throughout the week of 12 November 2018.

These events, open to Invisalign trained doctors who use the iTero Intraoral Scanner, are designed to drive awareness of clear aligner therapy and popularise digital intraoral scanning.

By attending a Free Smile Assessment event, potential patients will be able to see first-hand what their desired smile could look like using the Invisalign Outcome Simulator.

Dan Gallagher, General Manager GP Channel UK\&I at Align Technology, said: 'We know that GPs reported an average of $1.5 x$ more Invisalign treatment starts when patients were shown an Invisalign Outcome Simulation with the iTero Scanner versus patients who weren't shown the simulation.

'I believe the Free Smile Assessment Week is a fantastic opportunity to raise awareness of Invisalign and its related clinical treatment opportunities to potential patients.'

Practices taking part in the Free Smile Assessment Week will also be listed on the Invisalign consumer website via a dedicated doctor locator feature and will be encouraged to leverage these activities by embarking on their own advertising campaigns to target prospective patients.

GDP Dr Nicola Mulhaire, who took part in earlier events, said: 'Our event was a great day and it was very well received by consumers. I saw five prospective patients, four of whom are proceeding with Invisalign treatment.'

The Invisalign Free Smile Assessment Week is being supported by the European Aligner Society (EAS).

Its President Emeritus, Dr Graham Gardner said: 'EAS wishes to congratulate Align Technology on achieving their one millionth patient in EMEA - an incredible milestone that confirms aligner therapy as a mainstream, predictable system for aligning teeth.'

\section{Another level orthodontic training}

For dentists that have successfully completed the ClearSmile Brace 2-day hands-on certification course or ClearSmile Brace 1-day certification course, the IAS Academy is offering IAS Advanced comprehensive orthodontic training.

This level three theory and hands-on course trains dentists how to safely and effectively treat patients' whole dentition, even in complex cases. There are five modules in total, with course days running throughout 2018 and 2019. The programme will run as follows:

- Module 1: 22-24 November 2018

- Module 2: 23-26 January 2019

- Module 3: 25-27 April 2019

- Module 4: 12-14 September 2019

- Module 5: 5-7 December 2019.

To find out more about eligibility and learning objectives, or to secure a space on the programme, contact the IAS Academy directly.

More information on upcoming IAS Academy training courses is available at www.iasortho.com or by calling 02089162024 .

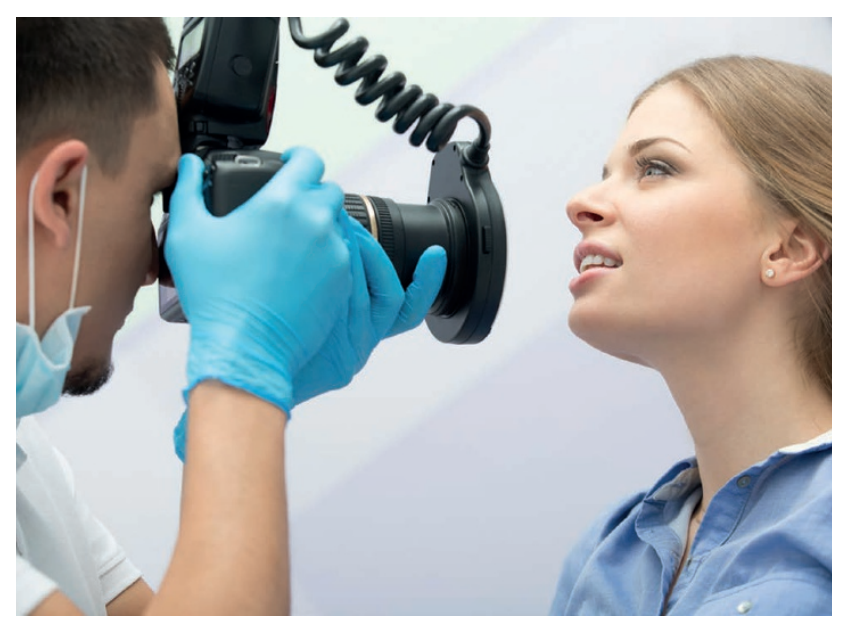

\section{Leader for a reason}

3M Oral Care demonstrated why it remains a leading provider of restorative, prosthodontic and orthodontic solutions at this year's recent BDIA Dental Showcase.

Among its latest innovations, the new and improved Impregum Super Quick polyether impression material was featured, offering the perfect balance of polyether precision and VPS speed.

Highlighting the longevity of their product lines, the team was celebrating 15 years of RelyX Unicem self-adhesive resin cement and delegates were able to discover for themselves why it has been so successful.

Also on display were the popular Filtek One bulk fill restorative, Scotchbond universal adhesive and Ketac universal glass ionomer.

For more information, call 0800626578 or visit www.3M. co.uk/Dental. 